\title{
Review: antidepressants reduce pain intensity in psychogenic pain or somatoform pain disorder
}

\author{
Fishbain DA, Cutler RB, Rosomoff HL, et al. Do antidepressants have an analgesic effect in psychogenic pain and somatoform pain \\ disorder? A meta-analysis. Psychosom Med 1998 Jul-Aug;60:503-9.
}

\section{Question}

Do antidepressants have an analgesic effect in patients who have psychogenic pain or somatoform pain disorder?

\section{Data sources}

Studies were identified by searching Medline, PsycINFO, and the National Library of Medicine databases (from 1966) and the Science Citation Index (from 1974). Search terms were pain, antidepressants, psychogenic pain, and somatoform pain disorder. Journals, books, and meeting abstracts on pain were handsearched.

\section{Study selection}

Studies in all languages were selected if they were randomised controlled trials that compared the effects of antidepressants with placebo on pain intensity in patients with psychogenic pain or somatoform pain disorder and if they reported $\mathrm{p}$ values. Studies on tension headache were included if the tension headaches were psychogenic. Studies that reported only statistically significant outcomes were excluded.

\section{Data extraction}

Data were extracted on methodological problems (10 item checklist), type of pain, study design, active drug dosage, sex of treated patients, trial length, use of a control for the presence of depression, and type of pain rating scale.

\section{Main results}

11 studies met the inclusion criteria. Study patients had atypical facial pain (2 studies), tension headache ( 5 studies), and mixed pain with a secondary diagnosis of psychogenic pain (2 studies).
1 study did not specify the type of pain, and 1 study included patients with head or neck pain (58\%), low back pain (66\%), and other types of pain (34\%). Patients were treated with amitriptyline (4 studies), dothiepin (1 study), femoxetine (1 study), zimelidine (1 study), phenelzine (1 study), clomipramine (1 study), maprotiline ( 1 study), and mianserin ( 1 study). Treatment duration ranged from 4 weeks to $\geqslant 3$ months, and follow up ranged from 4 weeks to 1 year. Sample sizes ranged from 22 to 366, and the number of methodological problems ranged from 1 to 6 . Effect sizes for each study were calculated and pooled. Antidepressants led to a greater reduction than placebo in pain intensity for overall pain $(\mathrm{p}<0.001)$, headache $(\mathrm{p}<0.01)$, and mixed pain $(\mathrm{p}<0.01)$ (table).

\section{Conclusion}

Antidepressants reduce pain intensity in patients with psychogenic pain or somatoform pain disorder.

Antidepressants v placebo in psychogenic or somatoform pain disorder

\begin{tabular}{llll}
\hline $\begin{array}{l}\text { Outcomes at 4-52 weeks of } \\
\text { follow up }\end{array}$ & No of studies & Effect size & $\begin{array}{l}\text { Controls with a worse } \\
\text { outcome than treated }\end{array}$ \\
\hline Overall pain intensity & 11 & 0.48 & $68 \%$ \\
Headache & Not reported & 0.59 & $72 \%$ \\
Mixed pain & Not reported & 0.39 & $65 \%$
\end{tabular}

*The proportion of control patients with a worse outcome than the average treated patient: calculated from data in article.

Source of funding: in part, National Institute of Disability and Disability Research

For correspondence: Dr D A Fishbain, Comprehensive Pain and Rehabilitation Center, South Shore Hospital, 600 Alton Road, South Miami Beach, FL 33319, USA. Fax +1 3055313065.

\section{Commentary}

The question about using antidepressants in non-psychiatric settings continues to intrigue. That antidepressants are effective in the treatment of depression, whether in the psychiatric, primary care, or general medical setting, is not in dispute. But physicians routinely use antidepressants for patients who are not obviously depressed, using doses and duration of treatment that their psychiatrist colleagues tell them are inadequate. The principal non-psychiatric indication is chronic pain, followed by (and overlapping with) sleep disorder. Previous metaanalyses have established the efficacy of antidepressants in neuropathic pain, principally diabetic neuropathy and postherpetic neuralgia. ${ }^{1}$ In this review, Fishbain et al tackle the more complex problem of chronic pain that arises without adequate biomedical explanation, which is labelled as somatoform pain disorder or psychogenic pain. These concepts are exceptionally problematic, however. ${ }^{2}$ As our knowledge of the central mechanisms involved in pain perception increases, the intellectual basis of the term psychogenic decreases. The authors exclude fibromyalgia but include atypical facial pain and tension headache, which are also purely subjective and symptom defined conditions. Another problem is the relation between depression and chronic pain-in this meta-analysis only 3 studies controlled for depression. The authors assume that because the other studies used doses or duration of antidepressants that are considered inadequate for the treatment of depression, this could not be the explanation for their efficacy. Psychiatrists base their views on the results of studies of moderate to severe depression in the specialist setting, however. We have little information on the efficacy of low dose antidepressants on mood in the general medical setting, and we cannot be sure that the analgesic effect reported here is not a primary mood effect. We already know that antidepressants are effective in depression irrespective of the aetiology of the illness. I suspect that much the same is true of chronic pain. Chronic pain is invariably multifactorial in origin. "Cure" is elusive and perhaps meaninglessinstead management is the goal of treatment, and antidepressants will have a part to play. Simon Wessely, MA, MSc, MD, MRCP,
MRCPsych
King's College School of Medicine and
Institute of Psychiatry
London, UK
McQuay HJ, Tramer M, Nye BA, et al. A system-
atic review of antidepressants in neuropathic
pain. Pain 1996;68:217-27.
Mayou R, Bass CM, Sharpe M, eds. Treatment of
functional somatic symptoms. Oxford: Oxford
University Press, 1995. 